\title{
EDITORSHIP AND POLICY
}

With this number of the Leprosy Review Dr Browne becomes Consulting Editor and the Editorial Board is joined by Dr Davey as Chairman. We pay tribute to the distinguished service to Leprology rendered by Dr Browne during the years he has been Chairman of the Editorial Board. In his new position we shall still have the benefit of his vast experience and inimitable personal contributions. It is a pleasure also to pay tribute to the valuable service to the Review rendered in recent years by ${ }^{2}$ Dr Duff behind the scenes. As sub-editor, Dr Duff brought to the Leprosy Review a lifetime of experience in medical journalism, and the technical excellence of the Review has been due in large measure to his meticulous attention to detail. We offer him our sincere gratitude, and best wishes for his retirement.

At this moment in time it is perhaps appropriate to declare once again the reasons for the existence of this Journal. The Leprosy Review came into being in 1930 to articulate and publicize the basic concerns of the British Leprosy Relief Association; namely, (a) the stimulation of research in leprosy, (b) the fostering of responsibility for the eradication of leprosy and the best possible care of those suffering from it, (c) the encouragement of those actually engaged in leprosy control work, through communicating advances in knowledge and the sharing of experience relating to common problems.

These basic concerns still stand, and all need to find expression in the pages of the Leprosy Review. On the research side the Leprosy Review has a distinguished record. There are few substantial advances in leprology in recent times that did not have their first notice in this Journal. It is fundamental that significant original work should be published without delay. There was a time when publication was possible within six weeks of the arrival of a contribution at the editorial office, as the writer knows from personal experience. Nowadays, printing and publication problems demand a minimum of two and a half months between the receipt of an article and its ultimate appearance in print. This period cannot appreciably be shortened, but in normal circumstances it need not be greatly exceeded. It will be our firm policy to "offer publication of original work acceptable to the Editorial Board with an absolute minimum of delay.

The past 15 years have witnessed enormous advances in our scientific knowledge of leprosy. Not only has $M y c o$. leprae been rehabilitated. Its unique properties have captured the interest and imagination of bacteriologists and immunologists at many centres, and its ongoing study is in the mainstream of 
medical research. Would that a corresponding wave of interest and concern were directed towards the people whose bodies have been invaded by Myco. leprae or are at high risk of encountering it. Progress in the control of leprosy lags far behind that already attained in the spheres of microbiology and immunology, and the reasons are not far to seek. The economic importance of leprosy is frequently underestimated. Its ancient and stubborn social implications pose a whole range of problems as varied as they are intractable, and which are outside the normal concerns of medical research. In studying these and in stimulating action in controlling leprosy and caring for those who suffer it, this Journal has a time honoured and independent role to play.

Finally, the large body of field workers engaged in the sometimes thankless task of trying to control leprosy has always been the special concern of LEPRA, and is therefore our special concern too. The tedium of maintaining circumscribed routines may be ennobled by dedication, but it may be sustained creatively if the individual worker continually has access to new knowledge and the experience of others who are similarly engaged. It is an important function of the Leprosy Review to serve the field worker in these directions, both where content and distribution are concerned. With this in view, a section devoted to "Leprosy and the Community" is introduced with this issue, presenting reports and material of interest to those directly engaged in leprosy control work. It is hoped to make this a regular feature of the Leprosy Review, and develop it further. Contributions and correspondence will be welcomed.

In addition to their value from the standpoint of research, the Committee Reports of the Bergen Congress include a great deal of material which should be essential reading for leprosy workers everywhere. For many years it has been the practice for the Expert Panel and Committee reports of Conferences of the International Leprosy Association to be published in the Leprosy Review, and precedent is again followed by the publication in this number of the Bergen Congress Committee Reports in full. 